\title{
Extending the functions of earth sciences in promoting sustainable development for mankind
}

In China's government structural reform early this year, the Ministry of Land and Resources was established through the reorganization of the Ministry of Geology and Mineral Resources, the State Bureau of Land Resources, the National Bureau of Oceanography, and the State Bureau of Surveying and Mapping. The new Ministry undertakes the planning, management, protection and rational utilization of natural resources including land, minerals and marine resources. It continues to develop relations of active cooperation and exchanges with other countries already established by the former Ministry of Geology and Mineral Resources. It also attaches great importance to maintain a good relationship with the International Union of Geological Sciences (IUGS). One of its offers is to take over the responsibility of providing support for Episodes.

The Ministry will promote the theme of the forthcoming 31st IGC - "Geology and Sustainable Development". While serving the cause of sustainable development, earth sciences in the 21 st century should pay special attention to the fundamental problems confronting human society, play greater roles in seeking solutions to the crises, promote people's understanding of nature, and continue to extend their functions and widen their scope of service.

Today, over $80 \%$ of industrial materials and $95 \%$ of energy come from mineral resources. For developing countries, including China, consumption of minerals will tend to increase for a long time to come. It will be the core task of earth sciences to prospect and exploit mineral resources so as to maintain sustainable development while meeting the current demand for minerals. Searching for "useful geologic bodies" through geological exploration (first category of ore prospecting) and exploring the "usability of geologic bodies" by means of technological innovation and technical development (second category of ore prospecting) will be the two supplementary orientations in the future. Along with the utilization of mineral resources from extensive to intensive, the second category of ore prospecting will become increasingly important.

The utilization of natural resources is a process of transforming the natural environment. The geological environment is the most fundamental material base in the whole environmental system. Changes in the geological environment are sometimes irreversible, therefore their effects on the various elements of the natural environment are most profound. Nowadays, mankind itself has become the most important geologic motive force. The issue of the geological environment has become increasingly critical as it interacts and combines with other environmental problems. Viewed from the large-scale ones such as volcanic eruptions, earthquakes, polar ice melting, mantle exhalation; the medium ones like soil erosion, regional permafrost, desertification, salinization; to the smaller ones such as landslides, mud flows and avalanche, the vulnerability of the geological environment and the frequency of geological hazards have become increasingly prominent problems. Geological hazards caused by big floods in the Yangtze River catchement in 1998 have been most startling, the losses amounting to over ten billion yuan (RMB). The study of environmental geology has been given attention since the 1970s worldwide, and the results achieved show that earth sciences are indispensable for solving the environmental problems that mankind is facing. Now it is time to place equal weight on environmental geology and resource exploration.

Earth sciences should not only serve industry (ore prospecting), but pay more attention to agriculture. New fields can be developed in the aspects of soil, water, fertilizers and forage. First, through studies of soil, rocks, minerals, hydrology and geomorphology, as well as of the formation and evolution of geologic bodies and the effects of weathering on trace elements, we can control the interrelations between rocks, minerals, soil and organisms in the migration, accumulation and balance of elements and in the water supply and demand system, so that the regional planning of agriculture and the patterns of crops can be based on a relatively strict geological background system. Second, we must carry out water conservancy and geological work for agriculture, which includes farmland water source investigation; groundwater recharging; engineering investigation and site selection for water conservancy projects; control of drought, water-logging and salinization; geothermal energy development; as well as irrigation, saving water for agricultural uses; prevention and control of water and soil pollution; and drainage for the preservation of fertilizers. Third, we must carry out studies to develop various kinds of mixed fertilizers, compound fertilizers, multi-trace element fertilizers, and low-cost substitutes for rock and mineral fertilizers and their rational applications. Fourth, we must improve the properties of mineral forage in such respects as easier digestion by livestock, fish and poultry; disease prevention; etc. Agricultural geology is a kind of geological work which deserves as much attention as does exploration geology; in terms of agricultural technology, it is as important as bio-engineering technology.

Earth sciences should serve the people more directly. Human bodies are the products of the evolution of crustal materials. The relationship between people's health and their geological background (water and soil) is a field worthy of exploration. Data on geological background can not only serve agriculture, but also become the basis of population-related earth sciences in the service of mankind. For example, the reconstruction after the devastating floods in China this year involves a great amount of geological studies concerning the planning of layouts for cities and towns as well as industrial sectors. Of course, the area of population-related earth sciences is much broader than what is cited here.

The Ministry of Land and Resources shall render comprehensive services to social-economic development. It is planning a new round of large-scale survey of land and resources. This survey is to be extended from land to sea, on the basis of strengthening basic geoscientific studies and using modern geoscientific technologies, putting equal stress on services for industry and for agriculture, as well as on mineral exploration and disaster mitigation. It incorporates social land surveys with comprehensive geoscientific research, and combines overall surveys with major breakthroughs. It pays attention to both the reinterpretation of available data and information sharing and the launching of new field investigations and laboratory research. The survey is jointly promoted by different mechanisms: that of the public, strategic and basic studies and that of market-oriented projects, aiming to enhance the level of protection and rational utilization of resources through rational planning and improved management.

It is our hope that the Chinese geoscientists will make greater efforts to serve the world geoscientific community, and that the progress of world geosciences will help further the noble task of sustaining the development of mankind.

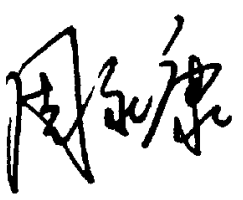

Zhou Yongkang

Minister of Land and Resources of China 